\title{
Optimization of ODHE Membrane Reactor Based of Mixed Ionic Electronic Conductor Using Soft Computing Techniques
}

doi:10.1016/j.ces.2010.12.013

\author{
M. P. Lobera ${ }^{1}$, S. Valero ${ }^{2}$, J. M. Serra ${ }^{1, *}$, S. Escolástico ${ }^{1}$, E. Argente $^{2}$, V.Botti ${ }^{2}$ \\ ${ }^{1}$ Instituto de Tecnología Química (Universidad Politécnica de Valencia - Consejo Superior de \\ Investigaciones Científicas), Avenida de los Naranjos s/n.46022 Valencia, Spain \\ ${ }^{2}$ Departamento de Sistemas Informáticos y Computación (DSIC). Universidad Politécnica de \\ Valencia. Camino de Vera s/n. 46020 Valencia, Spain
}

\section{Abstract}

This works presents the optimization of the operating conditions of a membrane reactor for the oxidative dehydration of ethane. The catalytic membrane reactor is based on a mixed ionic-electronic conducting material, i.e. $\mathrm{Ba}_{0.5} \mathrm{Sr}_{0.5} \mathrm{Co}_{0.8} \mathrm{Fe}_{0.2} \mathrm{O}_{\delta-3}$, which presents high oxygen flux above $750^{\circ} \mathrm{C}$ under sufficient chemical potential gradient. Specifically, diluted ethane is fed in the reactor chamber and air (or diluted air) is flushed on the other membrane side. A framework based on soft computing techniques has been used to maximize the ethylene yield by varying simultaneous five operation variables: nominal reactor temperature (Temp); gas flow in the reaction compartment (QHC); gas flow in the oxygen-rich compartment (QAir); ethane concentration in the reaction compartment $(\% \mathrm{C} 2 \mathrm{H} 6)$; and oxygen concentration in oxygen-rich compartment $(\% \mathrm{O} 2)$. The optimization tool combines a genetic algorithm guided by a neural network model. It is presented how the neural network model is obtained for this particular problem, and the analysis of its behaviour along the optimization process. The optimization process is analysed in terms of (1) catalytic figures of merit, i.e., evolution of yield and selectivity towards different products, and (2) framework behaviour and variable significance. The two experimental areas maximizing the ethylene yield are explored and analysed. The highest yield reached in the optimization process exceeded $92 \%$.

Keywords: Soft computing; neural network; genetic algorithm; ethylene; BSCF; membrane reactor; perovskite; ODHE; optimization.

* Corresponding author: Dr. José M. Serra. e-mail: jsalfaro@itq.upv.es 


\section{Introduction}

Selective oxidation reactions have emerged as alternative route to functionalize short chain paraffins in order to obtain olefins and oxygenated compounds. The difficulty in these processes lies in the fact that intermediates and target products are usually more reactive than the raw materials and therefore are prone to deeply oxidize to $\mathrm{CO}_{\mathrm{X}}$ (Blasco and López-Nieto, 1997; Bhasin, 2003). An example of these processes is the ethylene production through the oxidative dehydrogenation of ethane (ODHE). It represents a potential alternative process to steam cracking, which is the current principal method for industrial ethylene production. ODHE process is exothermic, while dehydrogenation and cracking are endothermic, so energy efficiency is improved and the presence of oxygen minimizes coke formation. However, the use of pure oxygen or enriched air contributes to increase process costs and the coexistence of ethane and molecular oxygen leads to undesired combustion reactions (Grasselli, 1999; RebeilleauDassonneville et al., 2005; Cavani et al., 2007)

In this context, the use of membrane reactor technology could overcome those drawbacks of ODHE. Dense mixed ionic-electronic conducting membranes (MIEC) show good oxygen permeation at elevated temperatures without the need of external electrical loadings with a theoretical selectivity of $100 \%$. MIEC membrane reactors are highly attractive solutions for ODHE reaction since (i) both oxygen separation and reaction are integrated in the same unit (Blasco and López-Nieto, 1997; Lu et al., 2000a, 2000b; Plotkin, 2005) and (ii) ethylene is produced very selectively by avoiding the direct contact of oxygen and hydrocarbons, i.e., principally ethane and ethylene, and therefore minimizing the oxygen concentration in the reaction side.

However, the catalytic behavior of a membrane reactor is not only determined by the intrinsic catalytic and permeation properties of the membrane but also reactor parameters (fluid dynamics, temperature, feed gas composition, contact time, etc.) have influence on the obtained results. A typical lab-scale reactor configuration (Figure 1) includes: (i) a dense MIEC disk membrane; (ii) an oxygen-rich membrane compartment where a mixture of synthetic air and nitrogen is fed; and (iii) a reaction compartment where a stream of ethane diluted in argon was fed. Operation temperature is kept in the range between 750 and $900^{\circ} \mathrm{C}$. 
The main purpose of this study is to optimize the operating conditions of high temperature catalytic membrane reactors. Using a framework based on Soft Computing techniques, it is intended to find the most suitable operating conditions to maximize the yield of ethylene in the oxidative dehydrogenation of ethane (ODHE) in a membrane reactor. The complexity of this optimization lies in the coupling of several processes such as: (i) complex mass transfer phenomena between the gas-phase and the membrane surfaces are defined by hydrodynamic conditions in both compartments; (ii) the ODHE reaction, especially the secondary reactions of degradation of the produced ethylene, and (iii) transport phenomena and separation of solid state oxygen through the dense ceramic membrane.

The term Soft Computing refers to the combined use of different computational techniques and methodologies that can tolerate some level of imprecision, uncertainty and information partially true, being able to obtain low-cost solutions while maintaining the necessary robustness and flexibility (Zadeh, 2004). Thus, this kind of solutions combines fuzzy logic, neural computing, genetic algorithms, machine learning, probabilistic reasoning, etc (Kecman, 2001). Regarding chemical engineering and catalysis field, the Soft Computing techniques have been employed to solve complex combinatorial problems, in which to work with multi-dimensional predictive models (Serra et al., 2003a; Klanner et al., 2003; Gilardoni et al., 2003) is necessary for using the previously extracted knowledge from the experimentation in the following optimization cycles.

As mentioned before, in this work a Soft Computing optimization framework was applied to optimize the operating conditions required to maximize the ethylene yield in the ODHE reaction. This framework combines Neural Networks (NN) and a real-coded Genetic Algorithm (GA), which were successfully employed in previous optimizations of heterogeneous catalysts (Corma et al., 2005; Serra et al., 2007; Valero et al., 2009). Specifically, the NN is used as an approximate model for fitness evaluation, whereas the GA finds suitable solutions by analyzing several alternatives simultaneously.

For this reason, Soft Computing techniques can be employed to optimize the ethylene yield by exploring concurrently different operation variables in an ODHE membrane reactor. The operation conditions included: (i) nominal reactor temperature; (ii) gas flow in the reaction compartment; (iii) hydrocarbon concentration in the reaction 
compartment; (iv) gas flow in the oxygen-rich compartment; and (v) oxygen concentration in such compartment.

\section{Related work: advanced computation in chemical engineering}

In recent years, examples of the application of Soft Computing techniques have been numerous, either in the design of experiments, kinetic modelling, and reaction conditions optimization or in the search for new materials in the field of catalysis.

In heterogeneous catalysis, the first applications of $\mathrm{NN}$ were reported for the design of solid catalysts (Hattori and Kito, 1995) for different reactions of interest, such as the design of catalysts for the ammoxidation of propylene (Hou et al., 1997), catalysts for oxidative coupling of methane (Huang et al., 2001) and the analysis and prediction of NO decomposition over Cu\ZSM-5 zeolite (Sasaki et al., 2005).

$\mathrm{NN}$ have been also applied combined with evolutionary strategies in the design of catalysts for the ammoxidation of propane (Cundari et al., 2001) and the discovering of new materials for the ODHE reaction (Corma et al., 2002a). Specifically, this work presents the analysis and prediction of catalytic results obtained by combinatorial techniques. Furthermore, NN were employed in the modeling of multiphase crystalline systems in the synthesis of zeolites (Moliner et al., 2005; Corma et al., 2006).

Concerning kinetic modeling, there are diverse applications in which kinetic experimental data have been modeled using NN's while making possible the fast modeling of series of catalysts and/or reaction conditions, and the rapid determination of optimal operation conditions and catalytic yield for each catalyst (Bulsari, 1995; Alaradi and Rohani, 2002; Biniwale et al., 2002; Serra et al., 2003b).

Support Vector Machine (SVM) has also been successfully employed as models. For example, Omata et al., 2010 used SVM to model the correlation between the oxide composition and catalytic activities (using the acidity and specific surface area as inputs) of the Si-Al-Zr ternary oxide system.

GA's have also been successfully applied in the development and optimization of catalysts used in light paraffin isomerization (Corma et al., 2002b), in the oxidation of 
the carbon monoxide (Pereira et al., 2005) and in the oxidative dehydrogenation of propane (Wolf et al., 2000). Furthermore, GA's have been employed to discover new homogeneous catalysts using the oxidation of methane by molecular oxygen as a model system (Kreutz et al., 2010).

Moreover, in Valero et al., 2004 a Soft Computing technique allows obtaining the best kinetic values for several n-paraffin reactions inside a specific range of input values to be determined. Based on this Soft Computing approach, catalysts for the epoxidation of olefins were optimized, where the synthesis variables of mesoporous Ti-silicate materials were intensively and simultaneously explored (Corma et al., 2005)

Other proposals based on Soft Computing techniques have been effectively applied in catalysis. For example, some evolutionary techniques were applied to design fuel additives (Ghosh et al., 2000; Sundaram et al., 2001). Specifically, the additive yield is predicted by means of a NN, whereas a GA (especially designed for addressing that problem) is used for finding the most convenient additives structures. Another interesting work was performed by Nandi et al., 2002, 2004, where NN's and GA's are used for the optimization of reactor operating conditions in the hydroxylation of benzene catalyzed by titanium silicalite zeolite (TS-1). In another approach, the temperature gradient profile in the reactor for the synthesis of dim-ethyl ether was optimized using a simple binary genetic algorithm, assisted by a NN modeling the catalytic activity (Omata et al., 2003).

\section{Experimental and Computational Procedure}

\subsection{Membrane Reactor Set-up and ODHE Experiment}

The catalytic tests were carried out in a quartz reactor placed inside a tubular electrical furnace. The temperature was measured by a thermocouple attached to the membrane. A PID controller maintained temperature variations within $2{ }^{\circ} \mathrm{C}$ of the set point. The measurements were performed on $15 \mathrm{~mm}$ diameter disks. The sample consisted of a gastight $\sim 0.8 \mathrm{~mm}$ thick BSCF disk sintered. The microstructure of the BSCF membranes was observed by scanning electron microscopy (SEM) in a JEOL JSM6300 electron microscope. 
Sealing was done using gold gaskets. Oxygen was separated from a mixture of synthetic air and $\mathrm{N}_{2}$. Permeate was analyzed by on-line gas chromatography using micro-GC Varian CP-4900 equipped with Molsieve5A, Pora-Plot-Q glass capillary, and CP-Sil modules. All streams were individually mass flow controlled. Membrane gas leak free conditions were ensured by monitoring nitrogen concentration on the products gas stream. Data reported are achieved at steady state after half an hour in reaction steam also each test has been repeated three times to minimize analysis error, obtained an experimental error less than $0.5 \%$. In addition, after 12 catalytic tests (reaction step), the sweep gas was shifted to argon during $12 \mathrm{~h}$ at $850^{\circ} \mathrm{C}$ (regeneration step), which allowed to maintain the perovskite phase of the membrane and regenerate the membrane surface (probably carbonated during the ODHE reaction) (Arnold et al., 2007). In order to ensure the membrane stability and the reproducibly of the experimental procedure, a control test was periodically repeated after 2 reaction-regeneration cycles. Ethane conversion, ethylene selectivity and ethylene yield were defined as follows:

$$
\begin{aligned}
& X_{C_{2} H_{6}}=\frac{\sum_{i} \frac{n_{i}}{2} F_{i}^{\text {out }}-F_{C_{2} H_{6}}^{\text {out }}}{\sum_{i} \frac{n_{i}}{2} F_{i}^{\text {out }}} \times 100 \\
& S_{i}=\frac{\frac{n_{i}}{2} F_{i}^{\text {out }}}{\sum_{i} \frac{n_{i}}{2} F_{i}^{\text {out }}-F_{C_{2} H_{6}}^{\text {out }}} \times 100 \\
& \boldsymbol{Y}_{C_{2} H_{4}}=\frac{\boldsymbol{X}_{C_{2} H_{6}} S_{C_{2} H_{4}}}{100}
\end{aligned}
$$

where $i$ includes all the components with carbon atoms in the permeate gas stream, $n_{i}$ is the number of carbon atoms of component $i$, and $F_{i}$ is its molar flow.

\subsection{Methodology, Experimental Design and Optimization Architecture}

As mentioned above, the employed Soft Computing technique combines Neural Networks (NN's) and a real-coded Genetic Algorithm (GA), where NN's are used as approximate models for fitness evaluation, whereas the GA finds suitable solutions by analyzing several alternatives simultaneously (chromosomes). 
This Soft Computing technique consists of the following steps (figure 2): settingup; NN retraining, modeling of fitness function; and GA operators, simulated evaluation and control evaluation (In Valero et al., 2009 and Valero 2010 this framework is explained in detail):

(i) Setting-up. The problem must be properly codified; a starting generation is obtained (ensuring diversity). Then, the fitness of those chromosomes, which represent the reaction conditions sets in the present case study, is experimentally evaluated, and, subsequently, a suitable NN model is obtained by selecting the best topology and training parameters. Finally, GA parameters are established.

(ii) NN retraining. The $\mathrm{NN}$ model is updated in order to enhance its precision, employing the last control generation obtained, whose fitness was experimentally evaluated.

(iii) Modeling of fitness function. The $\mathrm{NN}$ is used to approximate the fitness value of a chromosome both in the crossover operator employed by the GA and in the simulated (in-silico) evaluation stage.

(iv) GA operators. The first mutation operator acts over some chromosomes, modifying some genes (which compose each chromosome and represent each variable under study) in a haphazard way, jumping randomly anywhere within the allowed gene domain. Second, the crossover operator is based on confidence intervals and proposes new solutions assisted by the NN. New chromosomes are obtained taking into account its fitness and the genetic material of the best ones of each generation. Both operators take into consideration the rules defined in the codification.

(v) Simulated evaluation. The chromosomes (reaction conditions sets, in the present case) are selected from a candidate generation, getting a control generation. This in silico selection is done by using the $\mathrm{NN}$ model, i.e., the chromosomes presenting the most promising fitness have more probabilities to be selected, according the approximations made by the NN. The resulting control generation size corresponds to a fixed percentage of chromosomes of 
the GA candidate generation. This control generation has to be experimentally evaluated in the membrane reactor.

(vi) Control evaluation, in this final step the fitness value of each chromosome that belongs to the control generation is experimentally evaluated. Thus, the approximation values of the fitness functions predicted by the $\mathrm{NN}$ are replaced by the experimental ones.

A real-coded codification is used, which was specifically developed to permit establishing rules at different levels that the obtained solutions must satisfy. For that reason, this codification allows studying diverse kinds of problems. In this case, the problem consists of optimizing the required operation conditions to maximize the ethylene yield in the ODHE, and its codification was shown in the figure 3. Each chromosome represents a particular operation condition set, which comprises five genes: (i) nominal reactor temperature (Temp); (ii) gas flow in the reaction compartment (QHC); (iii) gas flow in the oxygen-rich compartment (QAir); (iv) ethane concentration in the reaction compartment $(\% \mathrm{C} 2 \mathrm{H} 6))$; and $(v)$ oxygen concentration in oxygen-rich compartment (\%O2). In table 1 it is depicted the allowed range for each operation parameters studied. The objective function optimized by the GA is the same that the employed to calculate the fitness value assigned to each particular operation condition set or chromosome. Thus, the fitness value (Eq. 3) corresponds to the ethylene yield in the ODHE reaction.

The GA parameters employed ${ }^{1}$ were those obtained in a previous study (Serra et al., 2007). Moreover, the GA suggests 51 new operation conditions sets (chromosomes) in each new generation. However, only the $63 \%$ of those chromosomes are experimentally tested. These selected operation conditions sets constitute the control generation, and its fitness corresponds to the experimental ethylene yield results.

\footnotetext{
${ }^{1}$ Mutation probability $=5 \%$, genes mutated $=1 ; \alpha=0.9 ;$ parents $=10 \%$; population $=$ 51 ; reduction ratio $=37 \%$.
} 


\section{Results and Discussions}

\subsection{Experimental and Reproducibility Procedure}

As indicated above, this work was performed using a $\mathrm{Ba}_{0.5} \mathrm{Sr}_{0.5} \mathrm{Co}_{0.8} \mathrm{Fe}_{0.2} \mathrm{O}_{\delta-3}$ (BSCF) membrane reactor. This perovskite-material exhibits the highest oxygen permeation flux due to its high ionic and electronic conductivity. However, when BSFC membranes are exposed to $\mathrm{CO}_{2}$-containing gas mixtures, the oxygen permeation flux decreased. The original flux could also be recovered by switching back to $\mathrm{CO}_{2}$-free atmosphere at temperatures higher than $550{ }^{\circ} \mathrm{C}$. The degradation is associated to the fact that earth alkali metals (included in the perovskite structure) tend to form carbonates (Arnold et al., 2007; Yan et al., 2008) at temperatures below $800^{\circ} \mathrm{C}$. Moreover, when lower percentages of $\mathrm{CO}_{2}(<5 \%)$ are used, the carbonates layer reaches an equilibrium thickness that still allows oxygen permeation even though with a reduced performance. That indicates a competition between two reactions: (i) stabilization to perovskite phase due to oxygen permeation, as commonly known in literature (Vente et al., 2006); and (ii) carbonation. If no competition between these reactions would take place, the oxygen permeation flux would stop after a certain time in each applied $\mathrm{CO}_{2}$ concentration since a continuously increase of the carbonate would occur. In all reaction tests, the BSCF membrane showed a good chemical stability, in spite of the $\mathrm{CO}_{2}$ presence, likely due to the low concentration of $\mathrm{CO}_{2}$ in the reaction side and the high oxygen permeation flux. In addition, after each reaction cycle a regeneration step was carried.

The microstructure of the BSCF membranes is showed in the figure 4. Although some pores appear on the cross-section of the BSCF membrane before catalytic test (figure $4 a$ ), they are proved to be closed pores by the leakage test. Figure $4 b$ showed the facture cross-section of the membrane after $150 \mathrm{~h}$ on stream. The analysed area corresponds to the closest to the reaction side surface. The membrane morphology has undergone degradation and the formation of Ba-rich particles along the grain boundary, which might be due to segregation of different phases (mixed $\mathrm{Ba}$ and $\mathrm{Sr}$-carbonates) during the catalytic tests.

Reproducibility of the catalytic tests was carried out following the experimental procedure depicted above. A control test was repeated in the same operating conditions 
after 2 reaction-regeneration cycles. The values of ethylene yield obtained have a standard deviation of $\pm 1.5 \%$ (figure 5). Mostrar tambien selectividad

\subsection{Getting a Suitable NN Model}

As mentioned in section 3.2, it is necessary to study the different factors involved in the $\mathrm{NN}$ prediction performance in order to obtain a suitable NN model for the fitness approximation. In this case, the data employed to carry out this analysis comes from a previous experiment in which 27 operation conditions sets for the ODHE reaction where tested. Obviously, the variables and allowed range values were the same (table 1). This analysis consisted in the study of several topologies, training algorithms and learning parameters. Table 2 describes all the analyzed possibilities (6720 experiments). In all these experiments, a tangential activation function was employed, because this was postulated as a suitable option for the catalysis field in Serra et al., 2003. Due to the complexity of this analysis and the experimental procedure followed, this analysis was performed in advance (prior to membrane reactor starting up), since the reactor could not be stopped, or left to wait long enough to perform the steps necessary to get the NN.

In order to obtain a suitable NN topology, an incremental method based in the supervised learning was applied. Therefore, different topologies based on the multilayer perceptron were test. Starting by only one hidden layer and few neurons, the topology is modified increasing the number of neurons (double of inputs as maximum), repeating the process with two hidden layers. The training algorithms studied (Backpropagation and Backpropagation momentum) were those that offer good results for the majority kids of problems according with the literature when multilayer perceptrons are employed (Bishop, 1996; Duda et al., 2001).

As the initial number of samples was small (only 27), a cross-validation technique on the data set was used (Bishop, 1996). Using this technique, the training set was randomly divided into ten subsets of training, validating and testing samples. Therefore, each experiment was carry out with different combinations of subsets, taking into account the medium values of the predictions made in the test phase. 
A selection of the best experiments carried out is shown is table 3. The best performance was obtained for an NN model with 5 nodes in its input layer, 9 nodes in its $1^{\text {st }}$ hidden layer, 9 nodes in its $2^{\text {nd }}$ hidden layer and 1 node in its output layer and it was trained employing the Backprop with momentum training algorithm, and with the learning parameters $\eta=0.5, \mu=0.6$. This $\mathrm{NN}$ model was the selected model for the Soft Computing optimization technique.

\subsection{Soft Computing Optimization Evolution}

The optimization process consisted of an iterative process with 4 steps, i.e., 4 different generations. The Soft Computing framework suggested one starting generation of 51 random operation conditions sets (generation 1). In each of the next 3 iterations, a candidate generation of 51 possible operation condition sets was suggested while a control generation of 32 operation condition sets was selected and experimentally tested. Thus, the GA explored 204 possible solutions but only 147 where finally tested in the membrane reactor.

The evolution of the fitness obtained for the different solutions studied is shown in figure 6. Figure 6a shows the evolution of the fitness approximations (predictions of the $\mathrm{NN}$ ) followed by the candidates generations suggested by the GA. Specifically, in figure $6 \mathrm{~b}$ it is possible to observe how the control generations evolved, showing the fitness values (ethylene yields) obtained for the reaction conditions sets suggested by the Soft Computing framework. As can be also seen in figure 7, the evolution of the mean fitness values of ethylene yield for the different generations are quite similar in both cases, improving from one generation to another. Thus, the noise introduced by the $\mathrm{NN}$ prediction error does not alter apparently the performance of the Soft Computing framework.

Figure 8a shows the evolution of the conversion obtained for the four evolved generations. The highest value of ethane conversion was obtained in the generation 1 and they were achieved at low concentrations of ethane $(<2 \%)$, while in the fourth generation a higher ethane conversion was reached $(\sim 98 \%)$ with an ethane concentration $>10 \%$ even at high temperatures of reaction. Taking into account the evolution of the average ethane conversion along the optimization process (Fig. 8d), an improvement is achieved through the first optimization steps. In the second generation, 
an improvement in the ethylene selectivity is visible. Although, the highest selectivity to ethylene $(\sim 95 \%)$ is obtained in generation 1 , this corresponds to a rather low ethane conversion and therefore a low ethylene yield $(\sim 35 \%)$ was achieved (Fig. 8b). Fig. 8c shows the evolution of $\mathrm{CO}_{2}$ selectivity with the evolved generations. Similarly, the highest $\mathrm{CO}_{2}$ selectivity is observed for a particular operation conditions set (Temp = $900{ }^{\circ} \mathrm{C} ; \% \mathrm{C} 2 \mathrm{H} 6=1.5 \% ; \% \mathrm{O} 2=21 \%$ ) in generation 1 . This is ascribed to the diversity and the exploratory character of this first generation. It is possible to see in figure 8e and $8 \mathrm{f}$ that the methane selectivity slightly improves from the first to the fourth operation condition sets, while the $\mathrm{C}_{3}$ selectivity increases in the first iterations and then decreases in the last one.

Concerning the topology of the experimental space (ethylene yield), it seems that there are two areas maximizing the yield, i.e. an area located at high temperature $\left(875^{\circ} \mathrm{C}\right.$ or above) and an area located at moderate temperature $\left(850^{\circ} \mathrm{C}\right)$. The first one is a relatively large area, which combines high yields but considerable selectivity to secondary products $\left(\mathrm{C}_{3}\right.$ or methane), while the second one is a rather small area at certain combinations of $\mathrm{QHC}$ and $\% \mathrm{C} 2 \mathrm{H} 6$. This last area presents higher ethylene selectivity and it is studied more in detail in section 4.4. The optimization framework focused on the first broad high-yield zone, i.e. it converges toward higher reaction temperatures in the last optimization steps. Certainly, the GA identified a greater potential of improvement in this area although a singular maximum has been found at low temperature. This behavior would be due to the limitations of the NN models, because singularities or very particular maximum areas are not well modeled and predicted by them. This fact has been proved by looking to the predicted space by the $\mathrm{NN}$ models and will be shown in section 4.5 and figure 11. In the second generation, a significant qualitative improvement was obtained in the ethylene yield (candidates and control generations). However, the enhancement in the third and fourth generations is very slight, since the Soft Computing framework had been located in one region of the search space considered as a promising area of operating conditions.

Figure 9 shows the evolution of the mean square error ${ }^{2}$ (MSE) obtained by the model to predict the fitness of the different control generations suggested during the

\footnotetext{
${ }^{2}$ Mean square error $=\Sigma$ (real-predicted $)^{2} / \mathrm{n}$, where $\mathrm{n}$ is the number of samples.
} 
optimization process. As can be seen, the model was gradually adapting to the problem under study, as higher amount of experimental data becomes available.

\subsection{Promising Area Exploitation}

Considering the results proposed by the algorithm, a promising area of operating conditions was explored in detail although it was outside of the main area investigated by the Soft Computing framework during the last optimization steps. Figure 10 shows the ethylene yield obtained in this area as a function of different operating conditions. In this area, the ethylene selectivity remained almost constant at high values $\left(\boldsymbol{S}_{\boldsymbol{C}_{2} \boldsymbol{H}_{4}} \sim 90\right.$ \%) while $\mathrm{CH}_{4}\left(\boldsymbol{S}_{\mathrm{CH}_{4}} \sim 8 \%\right)$ was obtained as by-product. Ethane conversion increases with the temperature while ethylene selectivity slightly decreases due to higher selectivity of secondary reactions to form $\mathrm{CH}_{4}$ and $\mathrm{CO}_{\mathrm{X}}$. It can be observed that the maximum ethylene yield is at $850{ }^{\circ} \mathrm{C}$ (Figure 10a). These results are consistent with the reported by other authors with a similar membrane (Rebeilleau-Dassonneville et al., 2005; Wang et al., 2006). Figure 10b shows the ethylene yield as a function of the ethane concentration in the reaction mixture. As expected, the ethylene yield decreases when the ethane concentration increases in the feed although the ethylene productivity $\left(\mathrm{ml} / \mathrm{min} \mathrm{cm}^{2}\right)$ rises. Figure $10 \mathrm{c}$ shows the ethylene yield as a function of feed flow rate in the reaction side. The ethane conversion decreases with an increase of the feed flow rate because this implies a shorter residence time. The opposite trend is observed for the ethylene selectivity. A shorter residence time involves a lower probability of oxidation of the ethylene produced, so its selectivity increases. Thus, the ethylene yield reached a maximum when the feed flow rate in the reaction side was $400 \mathrm{ml}(\mathrm{STP}) / \mathrm{min}$. However, in the range of operating conditions studied, no clear influence of the oxygen content in the air side was seen (figure 10d).

\subsection{NN Modelling of Whole Experimental Space}

It this section, it is shown the modeling results with the NN model fitted using the experimental data obtained during the membrane reactor operation. Thus, all the experimental data obtained during the optimization process and those obtained during the process of exploitation of a promising are were employed. Therefore, the 178 samples (conditions sets) were split into training $(80 \%)$, test $(10 \%)$ and validation 
$(10 \%)$ data sets. A MSE of 0.0289 was obtained for the performance of this NN when it approximates the fitness value of the test samples.

Concerning the topology of the NN in silico space used by the Soft computing framework during the optimization, Figure 11 shows 2D contour representations taking into account the three most important variables, i.e. hydrocarbon feed flow rate QHC, ethane concentration in feed \%C2H6 and temperature. Specifically, Figure 11 shows the variation of $\mathrm{QHC}$ and \% $2 \mathrm{H} 6$, varied in the whole range studies -Table 1- for three different temperatures. When increasing the operating temperature the high-yield area is larger although the selectivity toward secondary products increases. There exists always an area at high QHC and medium-to-high $\mathrm{C} 2 \mathrm{H} 6 \%$, which maxims the ethylene yield. However, at $850^{\circ} \mathrm{C}$ it cannot be observed the local maximum at $\mathrm{C} 2 \mathrm{H} 6 \%=2 \%$ and $\mathrm{QHC}$ $=400 \mathrm{ml}(\mathrm{STP}) / \mathrm{min}$ experimentally observed and this could be one of the reasons for the convergence towards the high-temperature maximum.

\section{Conclusions}

The optimization of the operating conditions of a membrane reactor for the oxidative dehydration of ethane is shown. The optimization algorithm combines a genetic algorithm and a neural network. The NN model is obtained using the experimental data from previous iterations and it is employed by the GA to in silico screen larger generation sizes and reduce the number of conditions to be experimental tested in the membrane reactor. This framework based on soft computing techniques has been used to maximize the ethylene yield by varying simultaneous five operation variables: nominal reactor temperature (Temp); gas flow in the reaction compartment $(\mathrm{QHC})$; gas flow in the oxygen-rich compartment (QAir); ethane concentration in the reaction compartment $(\% \mathrm{C} 2 \mathrm{H} 6)$; and oxygen concentration in oxygen-rich compartment $(\% \mathrm{O} 2)$. The most important variables are temperature and those related to the reaction compartment (\% $2 \mathrm{H} 6$ and $\mathrm{QHC})$. For a given temperature, there exists a certain combination of $\% \mathrm{C} 2 \mathrm{H} 6$ and $\mathrm{QHC}$, which maximizes the ethylene yield. Through the optimization process two maximums have been identified and explored. The framework explored thoroughly the high temperature maximum area. Moreover, it is shown how the NN model (topology, 
training algorithm and learning parameters) is obtained, and the analysis of its behaviour along the optimization process. The highest yield reached in the optimization process exceeded $92 \%$.

\section{Acknowledgments}

Financial support by the Spanish Ministry for Science and Innovation (Project ENE2008-06302 and FPI Grant JAE-Pre 08-0058), EU through FP7 NASA-OTM Project (NMP3-SL-2009-228701), and the Helmholtz Association of German Research Centres through the Helmholtz Alliance MEM-BRAIN (Initiative and Networking Fund) is kindly acknowledged.

\section{REFERENCES}

Alaradi, A.A., Rohani, S., 2002. Identification and control of a riser-type FCC unit using neural networks. Computers \& Chemical Engineering 26, 401-421.

Arnold, M., Wang, H. H., Feldhoff, A., 2007. Influence of $\mathrm{CO}_{2}$ on the oxygen permeation performance and the microstructure of perovskite-type $\left(\mathrm{Ba}_{0.5} \mathrm{Sr}_{0.5}\right)\left(\mathrm{Co}_{0.8} \mathrm{Fe}_{0.2}\right) \mathrm{O}_{3-\delta}$ membranes. Journal of Membrane Science 293, 44-52.

Bhasin, M.M., 2003. Is True Ethane Oxydehydrogenation Feasible? Topics in Catalysis 23, (2003) 145-149.

Biniwale, R.B., Labhsetwar, N.K., Kumar, R., Hasan, M.Z., 2002. Society of Automotive Engineers, Technical Papers 1676, 49-54.

Bishop, C., 1996. Neural Networks for Pattern Recognition. Oxford Clarendon Press. Oxford.

Blasco, T., Lopez Nieto, J.M., 1997. Oxidative dyhydrogenation of short chain alkanes on supported vanadium oxide catalysts. Applied Catalysis A: General 157, 117142.

Bulsari, A.B., 1995. Neural Networks for Chemical Engineers. Elsevier. Amsterdam.

Cavani, F., Ballarini, N., Cericola, A., 2007. Oxidative dehydrogenation of ethane and propane: How far from commercial implementation? Catalysis Today 127, 113131. 
Corma, A., Serra, J.M., Argente, E., Botti, V., Valero, S., 2002a. Application of artificial neural networks to combinatorial catalysis: modeling and predicting ODHE catalysts. ChemPhysChem 3, 939-945.

Corma, A., Serra J.M., Chica, A., 2002. Application of genetic algorithms to the development and optimisation of light paraffin isomerisation catalysts. Kluwer Academic Press, Dordrecht, 153-172.

Corma, A., Serra, J.M., Serna, P., Valero, S., Argente, E., Botti, V., 2005. Optimisation of olefin epoxidation catalysts with the application of high-throughput and genetic algorithms assisted by artificial neural networks (softcomputing techniques). Journal of Catalysis 229, 513-524.

Corma, A., Moliner, M., Serra, J.M., Serna, P., Díaz-Cabañas, M.J., Baumes, L.A., 2006. A new mapping/exploration approach for HT synthesis of zeolites. Chemistry of Materials 18 (14), 3287-3296

Cundari, T.R., Deng, J., Zhao,Y., 2001. Design of a propane ammoxidation catalyst using artificial neural networks and genetic algorithms. Industrial \& Engineering Chemistry Research 40 (23), 5475-5480.

Duda, R.O, Hart, P.E., Stork D.G. 2001. Pattern Classification. 2nd Ed. Jonh Wiley \& Sons

Ghosh P., Sundaram A., Venkatasubramanian, V., Caruthers, J. M., 2000. Integrated product engineering: a hybrid evolutionary framework. Computers \& Chemical Engineering 24 (2-7), 685-691.

Gilardoni, F., Graham, A., McKay, B., Brown, B., 2003. Rational design, an alternative to the combinatorial explosion, Proceeding of 225th ACS national meeting New Orleans (March 2003).

Grasselli, R.K., 1999. Advances and future trends in selective oxidation and ammoxidation catalysis. Catalysis Today 49, 141-153.

Hattori, T., Kito, S., 1995. Neural network as a tool for catalyst development. Catalysis Today 23, 347-355.

Hou, Z.Y., Dai, Q.L., Wu, X.Q., Chen, G.T., 1997. Artificial neural network aided design of catalyst for propane ammoxidation. Applied Catalysis A: General 161, 183-190.

Huang, K., Chen, F.Q., Lu, D. W., 2001. Artificial neural network-aided design of a multicomponent catalyst for methane oxidative coupling. Applied Catalysis A: General 219, 61-68. 
Kecman, V., 2001. Learning and Soft Computing: Support Vector Machines, Neural Networks, and Fuzzy Logic Models. MIT Press. Cambridge, MA, USA.

Klanner, C., Farruseng, D., Baumes, L., Mirodatos, C., Schüth, F., 2003. How to design diverse libraries of solid catalysts? QSAR and Combinatorial Science 22 (7), 729736 .

Kreutz, J.E., Shukhaev, A, Du, W., Druskin, S., Daugulis, O., Ismagilov, R.F., 2010. Evolution of catalysts directed by genetic algorithms in a plug-based microfluidic device tested with oxidation of methane by oxygen. Journal of the American Chemical Society 132 (9), 3128-3132.

Lu, Y., Dixon, A.G., Moser, W.R., Ma, Y.H., 2000a. Oxidative coupling of methane in a modified $\gamma$-alumina membrane reactor. Chemical Engineering Science 55, 49014912.

Lu, Y., Anthony G. Dixon, A.G., Moser, W.R., Ma, Y.H., Balachandran, U., 2000b. Oxygen-permeable dense membrane reactor for the oxidative coupling of methane. Journal of Membrane Science 170, 27-34.

Moliner, M., Serra, J.M., Corma, A., Argente, E., Valero, S., Botti, V., 2005. Application of artificial neural networks to high-throughput synthesis of zeolites. Microporous and Mesoporous Materials 78, 73-81.

Nandi, S., Mukherjee, P., Tambe, S.S., Kumar, R., Kulkarni, B.D., 2002. Reaction modeling and optimization using neural networks and genetic algorithms: Case study involving ts-1-catalyzed hydroxylation of benzene. Industrial \& Engineering Chemistry Research 41 (9), 2159-2169.

Nandi, S., Badhe, Y, Lonari, J., Sridevi, U., Rao, B. S., Tambe, S.S., Kulkarni., B.D., 2004. Hybrid process modeling and optimization strategies integrating neural networks/support vector regression and genetic algorithms: Study of benzene isopropylation on hbeta catalyst. Chemical Engineering Journal 9 (2-3), 115-129.

Omata, K., Ozaki, T., Umegaki, T., Watanabe, Y., Nukui, N., Yamada, M., 2003. Optimization of the temperature profile of a temperature gradient reactor for dme synthesis using a simple genetic algorithm assisted by a neural network. Energy \& Fuels 17 (4), 836-841.

Omata, K., Yamazaki, Y., Kobayashi, Y., Yamada, M., 2010. Application of response surface method using rapid screening, support vector machine, and multiple regression on the acidity and activity of $\mathrm{Si}-\mathrm{Al}-\mathrm{Zr}$ ternary oxide. Journal of Combinatorial Chemistry 12 (4), 435-444. 
Pereira, S.R.M., Clerc, F., Farrusseng, D., Van der Waal, J.C., Marchmeyer, T., Mirodatos, C., 2005. Effect of the genetic algorithm parameters on the optimisation of heterogeneous catalysts. QSAR \& Combinatorial Science 24, 45-57.

Plotkin, J.S., 2005. The changing dynamics of olefin supply/demand. Catalysis Today $106,10-14$.

Rebeilleau-Dassonneville, M., Rosini, S., van Veen, A.C., Farrusseng, D., Mirodatos, C., 2005. Oxidative activation of ethane on catalytic modified dense ionic oxygen conducting membranes. Catalysis Today 104, 131-137.

Sasaki, M., Hamada, H., Kintaichi, Y., Ito, T., 2005. Application of a neural network to the analysis of catalytic reactions analysis of no decomposition over Cu/ZSM-5 zeolite. Applied Catalysis A: General 132 (2005) 261-270.

Serra, J.M, Corma, A., Chica, A., Argente, E., Botti, V., 2003a. Can artificial neural networks help the experimentation in catalysis? Catalysis Today 81 (3), 393-403.

Serra, J.M., Corma, A., Farruseng, D., Baumes, L., Mirodatos, C., Flego, C., Perego, C., 2003b. Styrene from toluene by combinatorial catalysis. Catalysis Today 81 (3), 425-436.

Serra, J.M., Corma, A., Valero, S., Argente, E., Botti, V., 2007. Soft computing techniques applied to combinatorial catalysis: A new approach for the discovery and optimization of catalytic materials. QSAR \& Combinatorial Science, 11-26.

Sundaram, A., Ghosh, P., Caruthers, J.M., Venkatasubramanian, V., 2001. Design of fuel additives using neural networks and evolutionary algorithms. AIChE Journal. 47 (6), 1387-1406.

Valero, S., Argente, E., Botti, V., Serra, J.M., Corma, A., 2004. Soft computing techniques applied to catalytic reactions. Lecture Notes in Artificial Intelligence $3040,550-559$.

Valero, S., Argente, E., Botti, V., Serra, J.M., Serna, P., Moliner, M., Corma, A., 2009. DoE framework for catalyst development based on soft computing techniques. Computers and Chemical Engineering 33, 225-238.

Valero, S. Arquitectura de búsqueda basada en técnicas soft computing para la resolución de problemas combinatorios en diferentes dominios de aplicación. $\mathrm{Ph}$. D. Thesis, D.S.I.C. Universidad Politécnica de Valencia (2010)

Vente, J.F., McIntosh, S., Haije, W.G.; Bouwmeester, H.J.M., 2006. Properties and performance of $\mathrm{Ba}_{\mathrm{x}} \mathrm{Sr}_{1-\mathrm{x}} \mathrm{Co}_{0.8} \mathrm{Fe}_{0.2} \mathrm{O}_{3-\delta}$ materials for oxygen transport membranes. Journal of Solid State Electrochemistry 10, 581-588. 
Wolf, D., Buyevskaya, O.V., Baerns, M., 2000. An evolutionary approach in the combinatorial selection and optimization of catalytic materials. Applied Catalysis A: General 200, 63-77.

Wang, H., Tablet, C., Schiestel, T., Caro, 2006. Hollow fiber membrane reactors for the oxidative activation of ethane. Catalysis Today 118, 98-103.

Yan, A., Liu, B., Dong, Y., Tian, Z.; Wang, D., Cheng, M., 2008. A temperature programmed desorption investigation on the interaction of $\mathrm{Ba}_{0.5} \mathrm{Sr}_{0.5} \mathrm{Co}_{0.8} \mathrm{Fe}_{0.2} \mathrm{O}_{3-\delta}$ perovskite oxides with $\mathrm{CO}_{2}$ in the absence and presence of $\mathrm{H}_{2} \mathrm{O}$ and $\mathrm{O}_{2}$. Applied Catalysis B: Environmental 80, 24-31.

Zadeh, L.A., 1994. Fuzzy logic, neural networks, and soft computing. Communications of the ACM 37, 77-84. 


\section{TABLES}

Table 1. Range of values allowed for the operation parameters studied

\begin{tabular}{llll}
\hline Operation Parameter & Minimum & Maximum & Delta \\
\hline Temp & $700^{\circ} \mathrm{C}$ & $900^{\circ} \mathrm{C}$ & 50 \\
$\mathrm{QHC}$ & $50 \mathrm{ml} / \mathrm{min}$ & $500 \mathrm{ml} / \mathrm{min}$ & 10 \\
QAir & $50 \mathrm{ml} / \mathrm{min}$ & $500 \mathrm{ml} / \mathrm{min}$ & 10 \\
$\% \mathrm{C} 2 \mathrm{H} 6$ & $1.5 \%$ & $14 \%$ & 0.5 \\
$\% \mathrm{O} 2$ & $2 \%$ & $21 \%$ & 0.5 \\
\hline
\end{tabular}


Table 2. NN topologies, training algorithms and training parameters studied

\begin{tabular}{|c|c|c|c|c|}
\hline \multicolumn{2}{|c|}{ NN topology } & \multicolumn{3}{|c|}{ Training algorithms } \\
\hline Layer & Neurons & Name & Par & ters \\
\hline Input layer & 5 & Backprop & $\eta=\{0.2,0.3,0.4$ & $0.6,0.7,0.8\}$ \\
\hline $1^{\text {st }}$ hidden layer & {$[1,10]$} & & & \\
\hline $2^{\text {nd }}$ hidden layer & {$[0,10]$} & Backprop & $\eta=\{0.2,0.3,0.4$ & $\mu=\{0.2,0.3,0.4$ \\
\hline Output layer & 1 & momentum & $0.5,0.6,0.7,0.8\}$ & $0.5,0.6,0.7,0.8\}$ \\
\hline
\end{tabular}


Table 3. Selection of NN models studied: mean square error in test (MSE)

\begin{tabular}{|c|c|c|c|c|c|c|}
\hline \multicolumn{4}{|c|}{ NN topology } & \multicolumn{2}{|c|}{ Training algorithms } & \multirow{2}{*}{$M S E$} \\
\hline In & $1^{\text {st }}$ & $2^{\text {nd }}$ & Out & Name & Parameters & \\
\hline 5 & 4 & 5 & 1 & Backprop & $\eta=0.8$ & 0.0173773612 \\
\hline 5 & 5 & 10 & 1 & Backprop Mom. & $\eta=0.2, \mu=0.7$ & 0.0153971969 \\
\hline 5 & 8 & 7 & 1 & Backprop Mom. & $\eta=0.3, \mu=0.7$ & 0.015035905 \\
\hline 5 & 9 & 6 & 1 & Backprop Mom. & $\eta=0.4, \mu=0.7$ & 0.0145730314 \\
\hline 5 & 9 & 9 & 1 & Backprop Mom. & $\eta=0.5, \mu=0.6$ & 0.0114666878 \\
\hline 5 & 9 & 2 & 1 & Backprop Mom. & $\eta=0.6, \mu=0.7$ & 0.0146375867 \\
\hline 5 & 7 & 9 & 1 & Backprop Mom. & $\eta=0.7, \mu=0.7$ & 0.0123018692 \\
\hline 5 & 4 & 4 & 1 & Backprop Mom. & $\eta=0.8, \mu=0.6$ & 0.0131072584 \\
\hline
\end{tabular}




\section{FIGURE CAPTIONS}

Fig. 1. Schematics of the lab-scale membrane reactor design.

Fig. 2. Steps of the applied Soft Computing Technique to optimize the MIEC-catalytic membrane reactors.

Fig. 3. Problem codification. Example of a chromosome that represents a particular operation conditions set, formed by five genes which correspond to five operating conditions employed in the optimization. The established rules are: minimum, maximum, allowed increments (delta) values for the different genes.

Fig. 4. SEM pictures of the fracture cross-section of $\mathrm{Ba}_{0.5} \mathrm{Sr}_{0.5} \mathrm{Co}_{0.8} \mathrm{Fe}_{0.2} \mathrm{O}_{3-\delta}$ (BSCF) membrane: (a) before catalytic tests, (b) after catalytic tests.

Fig. 5. Ethylene yield evolution using the same experimental condition as reproducibility test. Temp $=800{ }^{\circ} \mathrm{C}, \mathrm{QHC}=50 \mathrm{ml}(\mathrm{STP}) / \mathrm{min}, \mathrm{QAir}=420 \mathrm{ml}(\mathrm{STP}) / \mathrm{min}$, $8.4 \% \mathrm{C} 2 \mathrm{H} 6,18.5 \% \mathrm{O} 2$. Each point was repeated three times within a $0.1 \%$ S.D.

Fig. 6. Oxidative dehydrogenation of ethane behaviour (ethylene yield) for the four generations: (a) Predicted performance for the different candidates (51 sets) suggested in each generation; and (b) Experimental results obtained in the control generations (32 sets).

Fig. 7. Mean ethylene yield for the different generations (candidates generations and control generations).

Fig. 8. Experimental results in terms of ethane conversion and selectivity toward the different reaction products for the four evolved control generations.

Fig. 9. Mean Square Error (MSE) evolution of the approximations made by the NN model through the optimization process. For each control generation, the MSE reached in the fitness approximation of its chromosomes is showed.

Fig 10. Ethylene yield, different operating conditions. (a) as a function of reaction temperature: $5.4 \% \mathrm{C} 2 \mathrm{H} 6,4 \% \mathrm{O} 2, \mathrm{QHC}=400 \mathrm{ml}(\mathrm{STP}) / \mathrm{min}$, QAir $=200 \mathrm{ml}(\mathrm{STP}) / \mathrm{min}$; (b) as a function of percentage of $\mathrm{C}_{2} \mathrm{H}_{6}$ in the feed: Temp $=850{ }^{\circ} \mathrm{C}, 4 \% \mathrm{O} 2, \mathrm{QHC}=400$ $\mathrm{ml}(\mathrm{STP}) / \mathrm{min}, \mathrm{QAir}=200 \mathrm{ml}(\mathrm{STP}) / \mathrm{min} ;$ (c) as a function of feed flow rate: Temp $=850$ 
${ }^{\circ} \mathrm{C}, 4 \% \mathrm{O} 2,5.4 \% \mathrm{C} 2 \mathrm{H} 6$, QAir $=200 \mathrm{ml}(\mathrm{STP}) / \mathrm{min}$; and $(\mathrm{d})$ as a function of percentage of $\mathrm{O}_{2}: \mathrm{Temp}=850{ }^{\circ} \mathrm{C}, 5.4 \% \mathrm{C} 2 \mathrm{H} 6, \mathrm{QHC}=400 \mathrm{ml}(\mathrm{STP}) / \mathrm{min}, \mathrm{QAir}=200 \mathrm{ml}(\mathrm{STP}) / \mathrm{min}$.

Fig 11. 2D space mapping plots obtained using the $\mathrm{NN}$ model trained with the whole experimental data. Uniquely the variables concerned with the hydrocarbon feed are considered for three different temperatures. The variation ranges is $50-500 \mathrm{ml}(\mathrm{STP}) / \mathrm{min}$ for QHC and 1.5-14\% for \%C2H6. The fixed variables are QAir (210 $\mathrm{ml}(\mathrm{STP}) / \mathrm{min})$ and $\% \mathrm{O} 2(5 \%)$. 
Figure 1

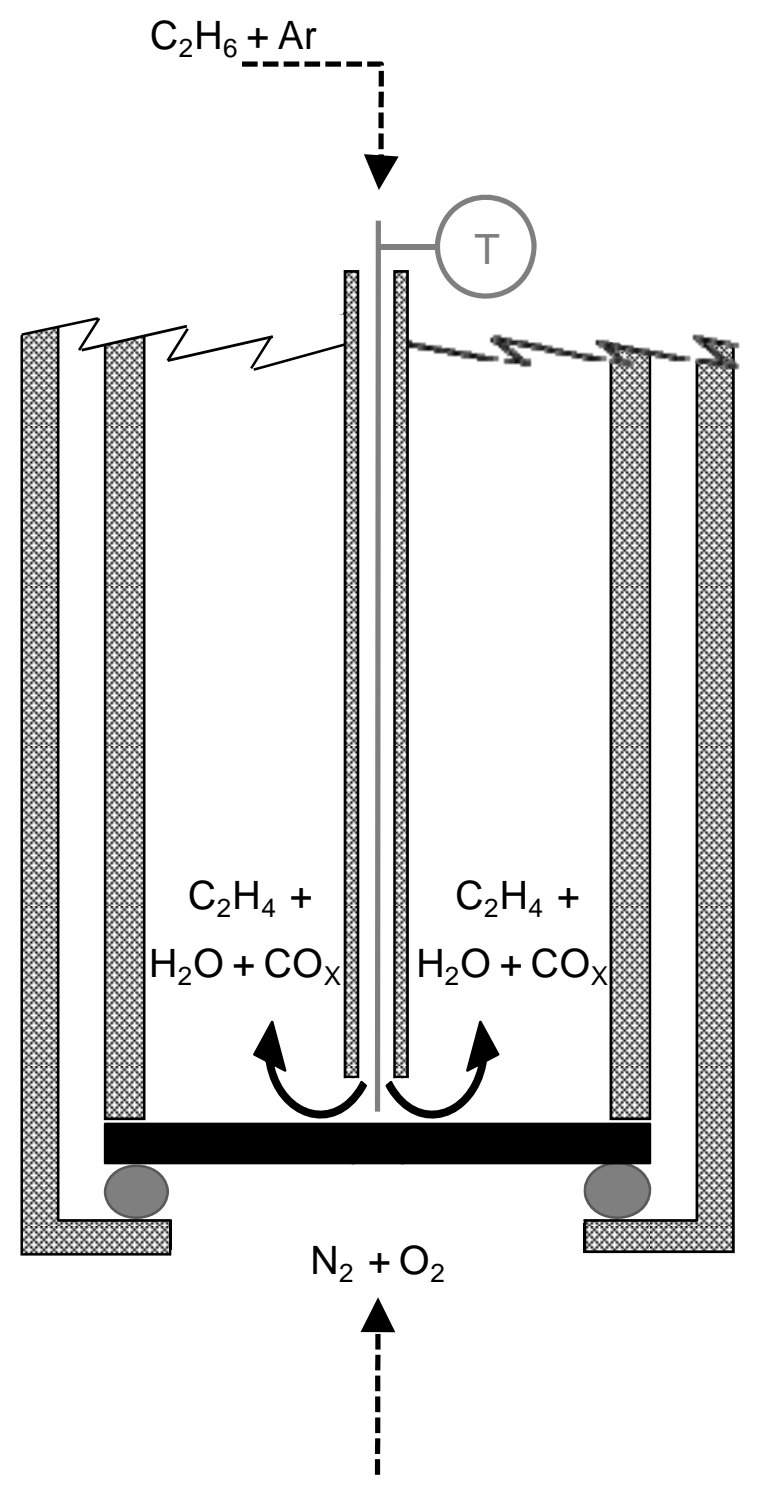


Figure 2

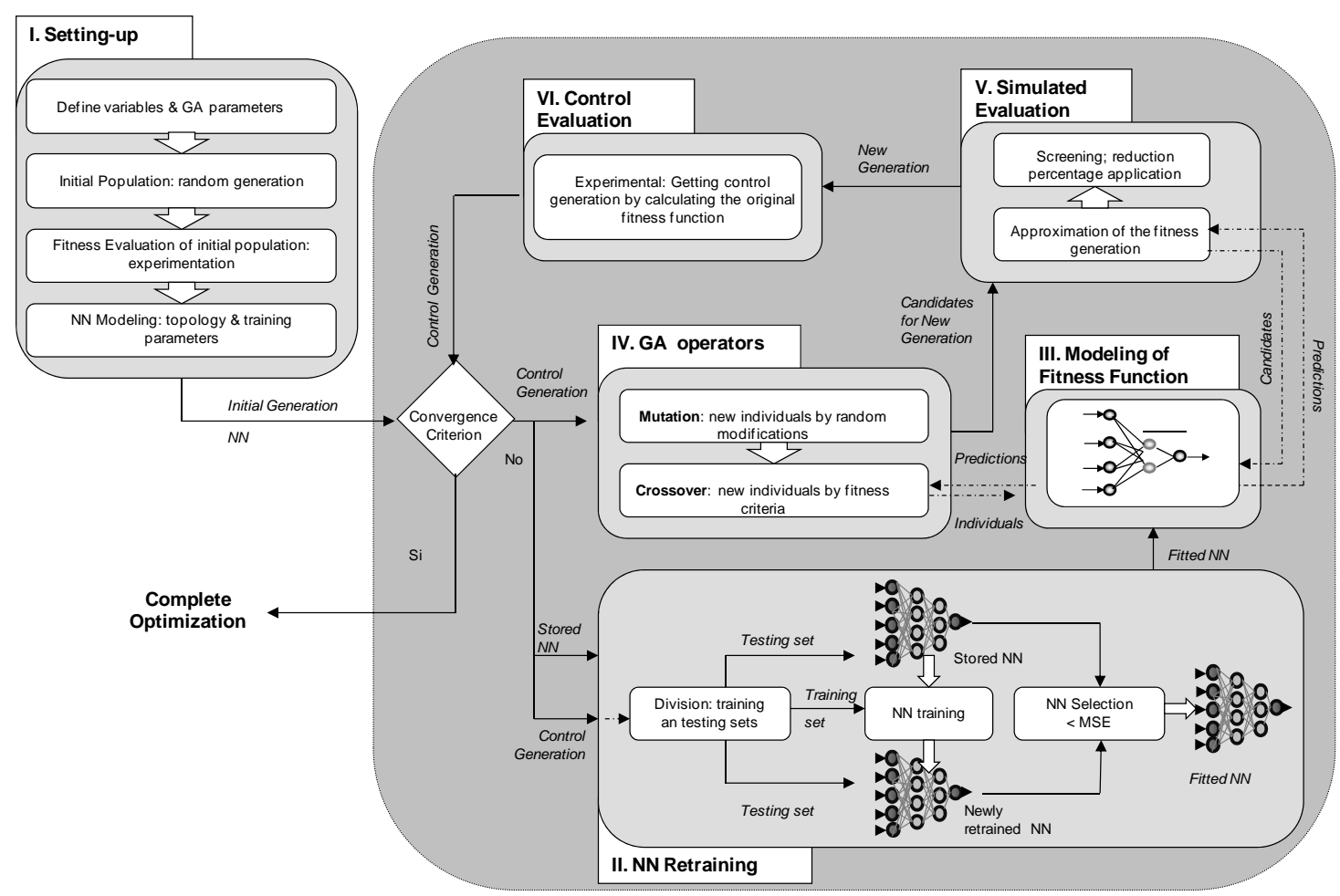




\section{Figure 3}

\section{MIEC Reactor Conditions : Chromosome}

Operation Conditions : Condition

Contitions: Type

Min $=803.05$

$\operatorname{Max}=1935$

Select $=1$

Value $=1506.13$

Conditions : Subtype

Min $=803.5$

Max $=1935$

Select $=5$

Value $=1506.13$

\begin{tabular}{|c|c|c|c|c|}
\hline Temp : Element & $\mathrm{QHC}$ : Element & QAir : Element & $\% \mathrm{C} 2 \mathrm{H} 6$ : Element & $\% \mathrm{O} 2$ : Element \\
\hline \begin{tabular}{|l} 
Min = 750 \\
Max = 900 \\
Delta = 5 \\
Value = 875
\end{tabular} & \begin{tabular}{|l} 
Min $=50$ \\
Max $=500$ \\
Delta $=10$ \\
Value $=393$
\end{tabular} & \begin{tabular}{|l} 
Min $=50$ \\
Max $=500$ \\
Delta $=10$ \\
Value $=220$
\end{tabular} & \begin{tabular}{|l|} 
Min $=1.5$ \\
Max = 14 \\
Delta =0.5 \\
Value $=7.63$
\end{tabular} & \begin{tabular}{|l} 
Min $=2$ \\
Max $=21$ \\
Delta $=0.5$ \\
Value $=10.5$
\end{tabular} \\
\hline
\end{tabular}


Figure 4
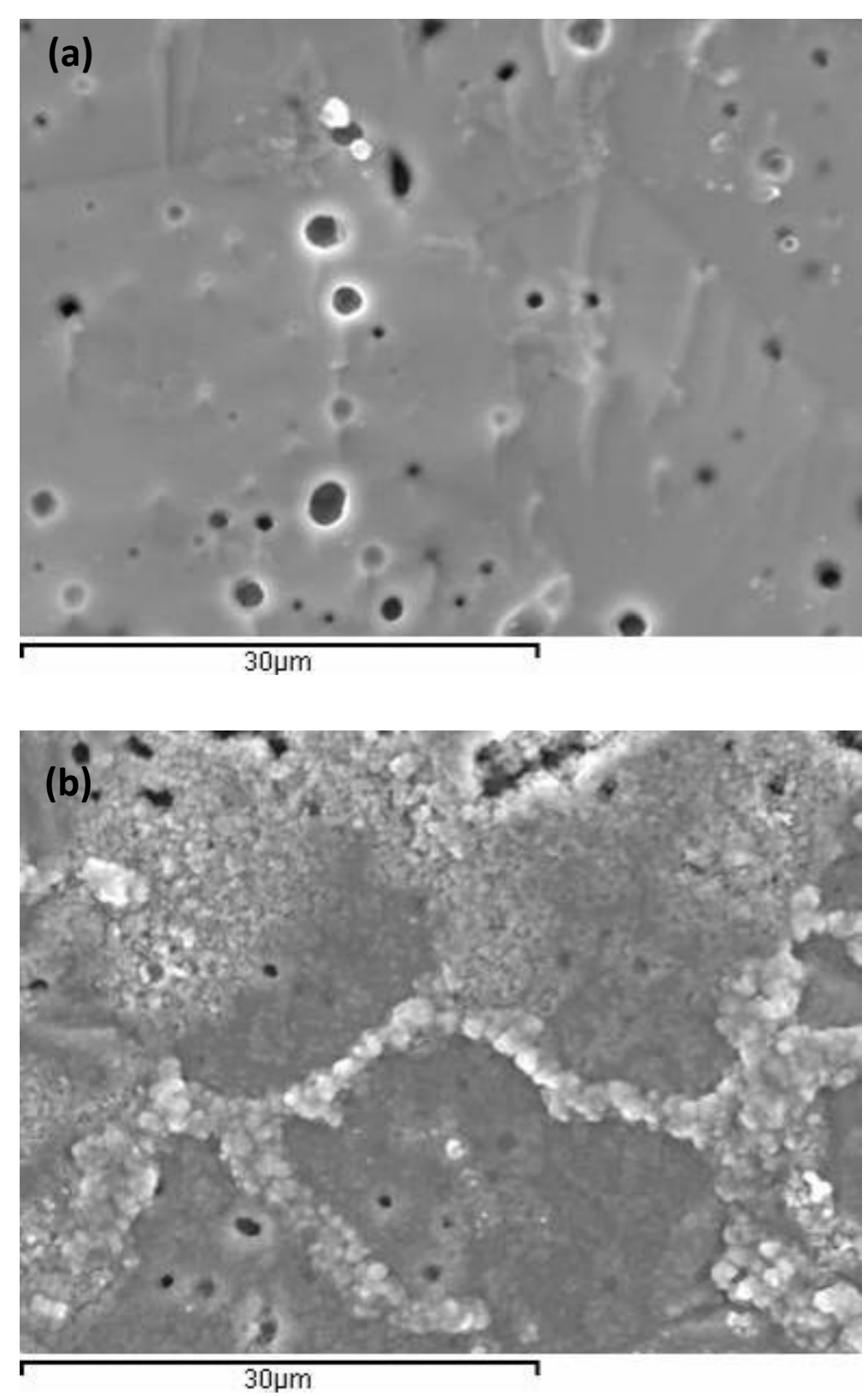
Figure 5

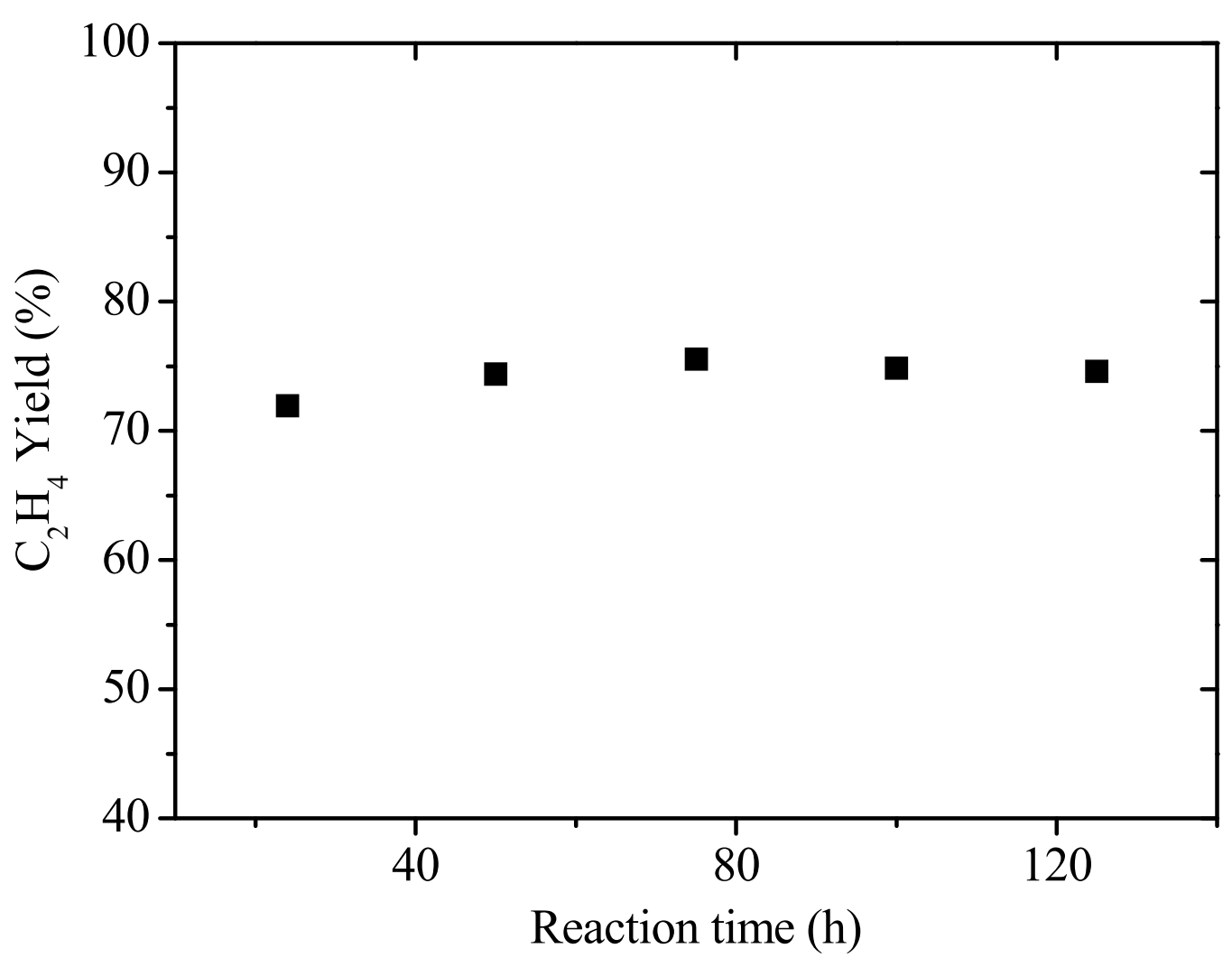


Figure 6
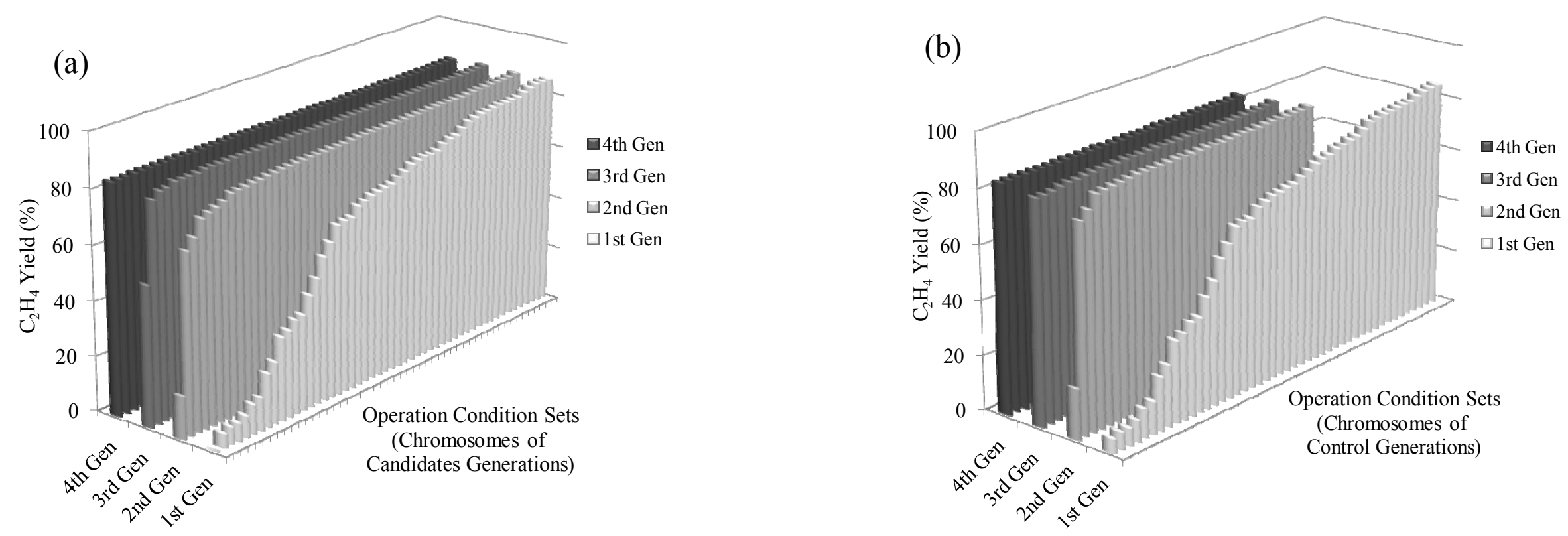
Figure 7

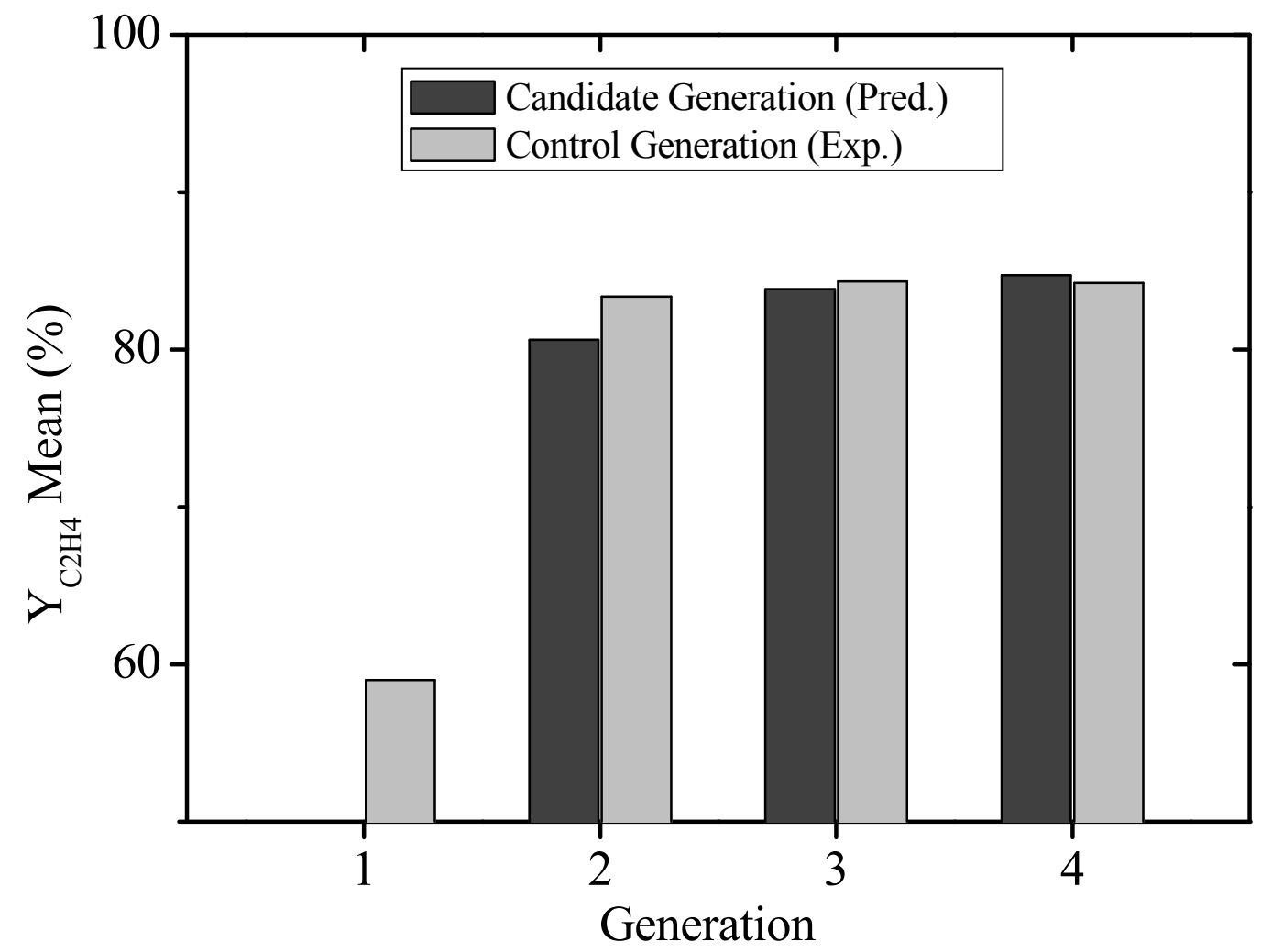


Figure 8

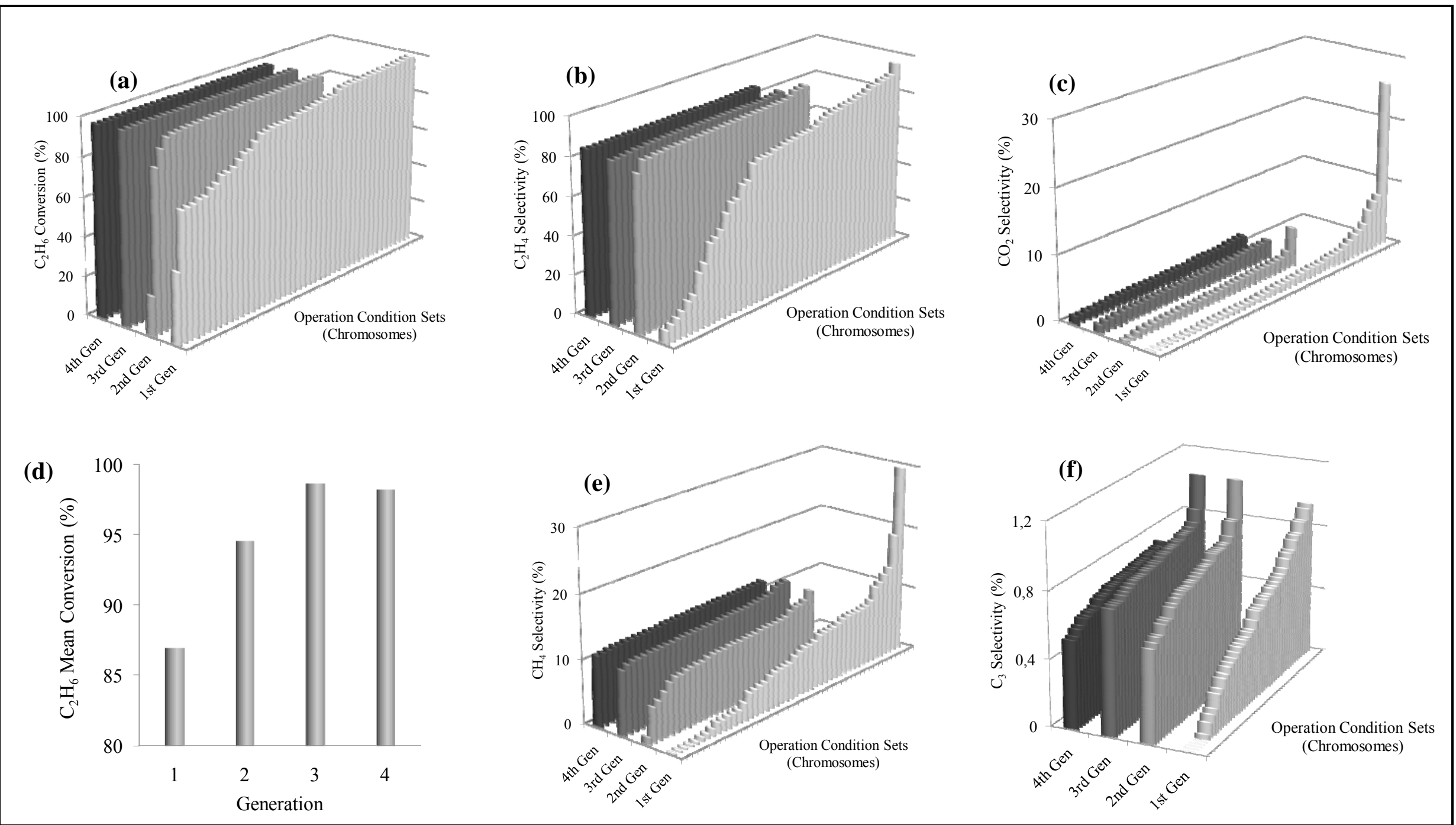


Figure 9

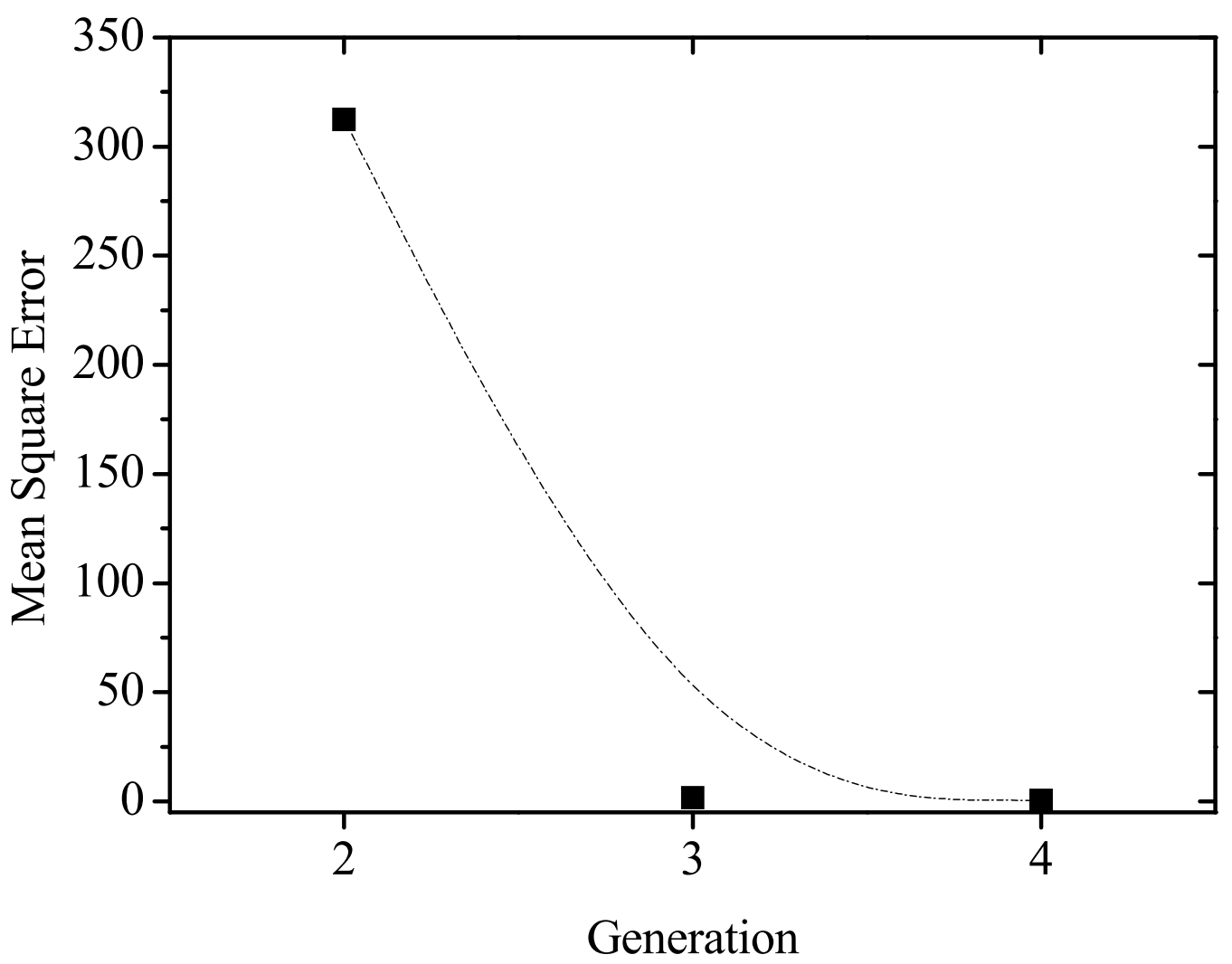


Figure 10
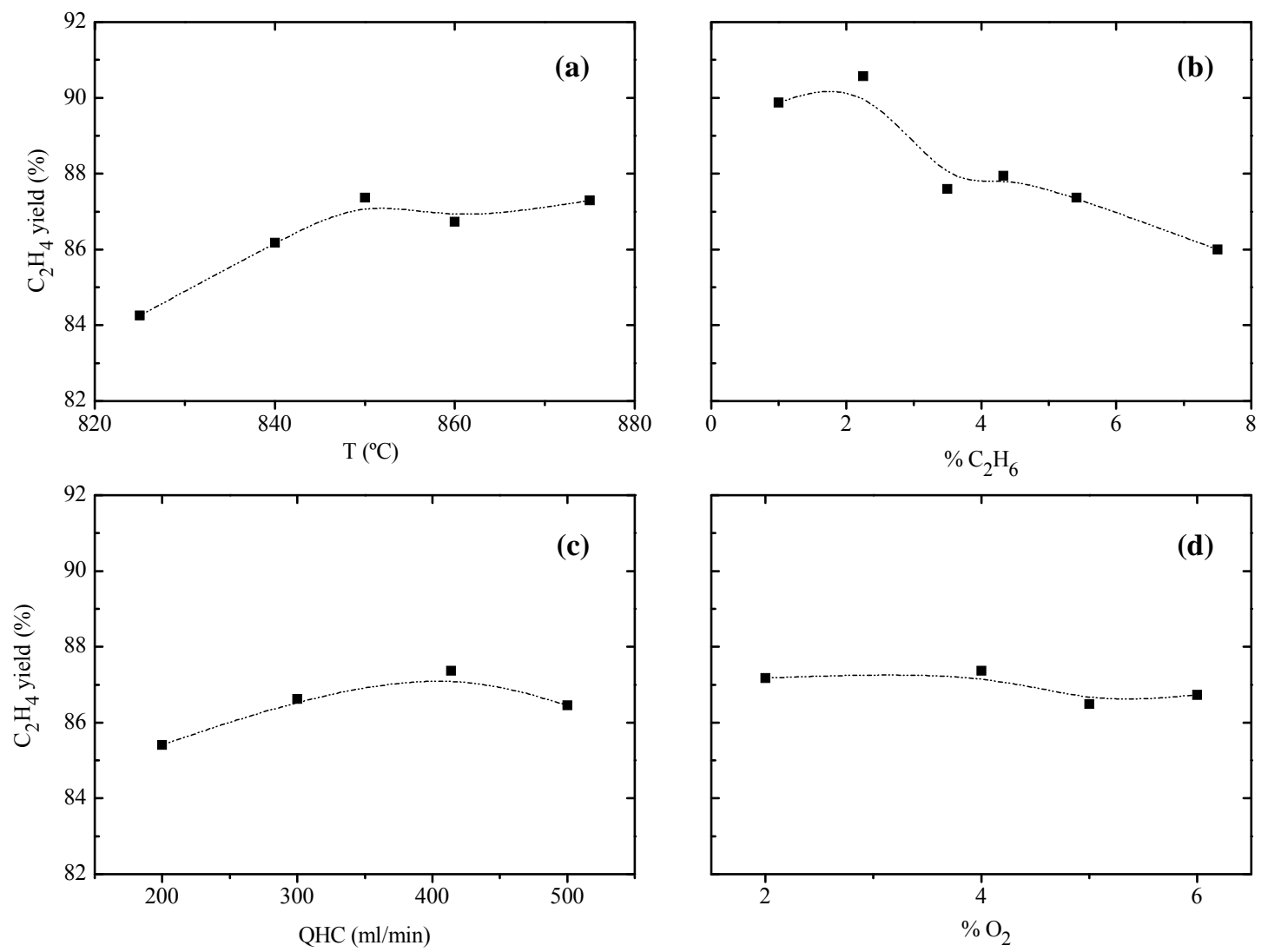
Figure 11

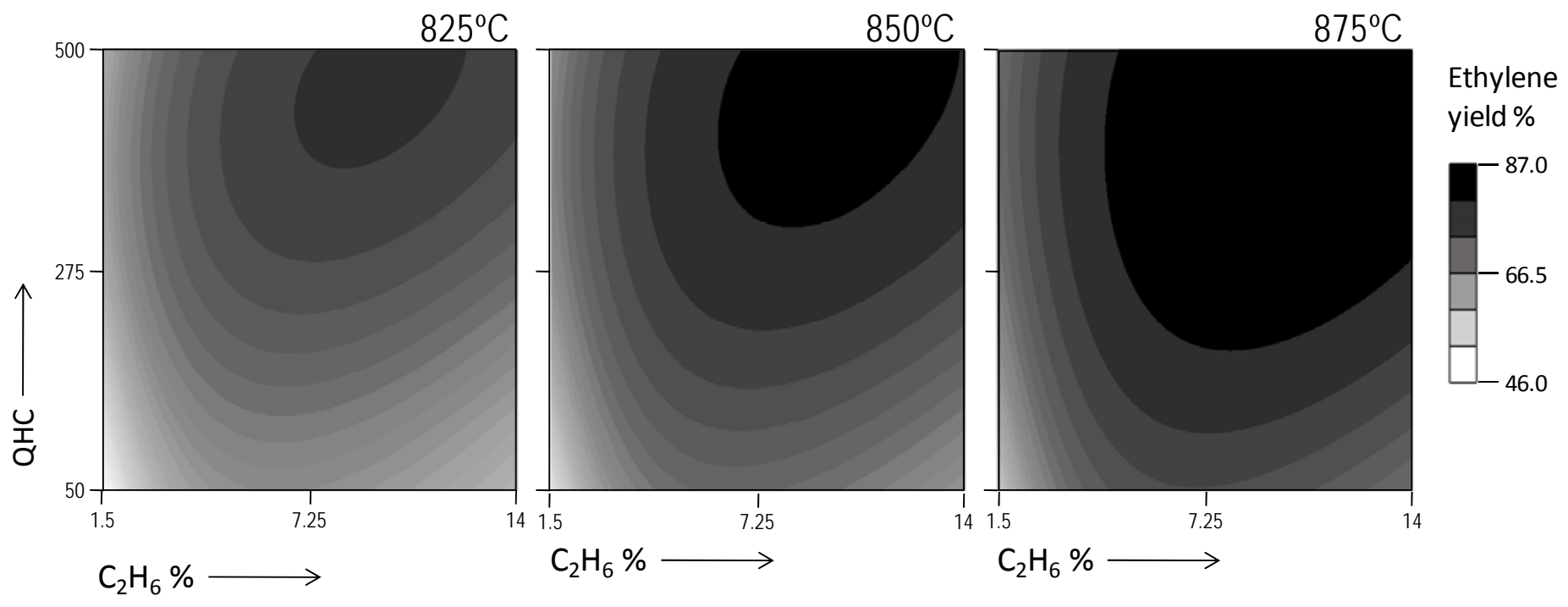

